\section{LIDERAZGO IGNACIANO Y GOBERNANZA EN LAS UNIVERSIDADES DE LA COMPAÑÍA DE JESÚS}

\author{
José María Guibert \\ Rector de la Universidad de Deusto \\ guibert@deusto.es
}

\section{IGNATIAN LEADERSHIP AND GOVERNANCE IN SOCIETY OF JESUS UNIVERSITIES}

Cómo citar este artículo/Citation: Guibert, J. M. (2016). Liderazgo ignaciano y gobernanza en las universidades de la Compañía de Jesús. Arbor, 192 (782): a364. doi: http://dx.doi. org/10.3989/arbor.2016.782n6009
Copyright: (c) 2016 CSIC. Este es un artículo de acceso abierto distribuido bajo los términos de la licencia Creative Commons Attribution (CC BY) España 3.0.
RESUMEN: Las universidades se enfrentan a múltiples retos que tienen ver con la misión que llevan a cabo en la sociedad en que se encuentran. La Compañía de Jesús en las últimas décadas ha renovado y reformulado de manera actualizada su misión. Es titular de casi doscientas instituciones de educación superior. Ha renovado también el entronque de dichas instituciones en la misión de la misma Compañía. El concepto de liderazgo ignaciano surge estos años como eje de renovación de personas e instituciones. Puede ser también, para las universidades jesuitas, ocasión de profundización en su identidad y de mejora en su servicio apostólico.

PALABRAS CLAVE: Universidad; jesuita; Compañía de Jesús; liderazgo; gobierno.
ABSTRACT: Universities are faced with many challenges associated with their mission in the societies in which they are found. In recent decades, the Society of Jesus has renovated and updated its mission with a new reformulation. It owns nearly two hundred institutions of higher education and there has been a reintegration of these institutions in the mission of the Society of Jesus. The concept of Ignatian leadership has emerged in recent years as a means of renewing individuals and institutions. For Jesuit universities this may, also, provide an opportunity to deepen their identity and improve their apostolic service.

KEYWORDS: University; Jesuit; Society of Jesus; leadership; governance. 


\section{INTRODUCCIÓN}

La principal característica de la gobernanza de las universidades de la Compañía de Jesús es el espíritu o marco ideológico que la misma Compañía quiere dar a sus instituciones de educación superior. Esto se enmarca en una tradición de gobierno de instituciones que en estos últimos años se está renovando alrededor del concepto de "liderazgo ignaciano".

La Compañía define actualmente sus instituciones de educación superior como instituciones con un sustantivo ("universidad") y un adjetivo ("jesuita"). Desde las distintas instancias de gobernanza jesuita se alienta, por un lado, a que estas instituciones sigan los criterios generales de las universidades en cuanto tales y sean así fieles a los retos que las universidades, en los distintos países y contextos, tienen actualmente. Y, por otro lado, se recuerda que como instituciones jesuitas, han de seguir las pautas de identidad y misión que la misma Compañía define y busca con todas sus instituciones.

\section{PAUTAS PARA EL APOSTOLADO INTELECTUAL DESDE LA COMPAÑÍA DE JESÚS}

Las Congregaciones Generales y los documentos oficiales de los Padres Generales son las fuentes en las que podemos ver con más claridad lo que oficialmente la Compañía de Jesús quiere proclamar. Una Congregación General es el órgano legislativo de máxima autoridad y se reúne cada 10-15 años, solo para sustituir al superior general o para tratar temas muy de fondo que el gobierno ordinario no puede atender. Una carta o discurso de un Padre General recoge también, se puede suponer, lo que la autoridad de la Compañía quiere destacar en cada momento y, evidentemente, tiene lugar con muchísima más frecuencia que una Congregación General (CG).

El Concilio Vaticano II (1962-1965) recogió para la Iglesia Católica nuevos aires que la cultura contemporánea requería y supuso el inicio de unos cambios y adaptaciones que probablemente han sido los más relevantes y determinantes de la historia de la Iglesia, exceptuando los del siglo I en que fue creada. La Compañía de Jesús, durante este medio siglo último, ha respondido en consonancia a esos retos de cambio y adaptación (aggiornamento) y sus Congregaciones Generales han marcado la guía y pauta de los nuevos conceptos que se han introducido en su proceso de adaptación al mundo actual.

Para el tema que nos ocupa, las universidades jesuitas y su gobierno, revisar algunos contenidos de
Congregaciones Generales y de cartas de los Padres Generales es el camino a seguir. Muestran qué temas se han querido destacar en estos cincuenta años de cambios. En este apartado mostramos, secuenciados temporalmente, una selección de referencias importantes que son suficientemente significativas para el fin que pretendemos. Recorremos el último medio siglo de vida de la Compañía y las pautas que desde el alto gobierno se han marcado en lo que respecta a las universidades jesuitas.

Recogemos en los párrafos que siguen, de manera sumaria, la problemática que se ha atendido y las respuestas que se han dado, desde el gobierno, en estos últimos cincuenta años.

\section{(A) Congregación General 31 (1965)}

Tres decretos de esta CG versan sobre el apostolado intelectual. El primero de ellos es el Dec. 28. "Apostolado de la educación". Cuando se habla de educación, se incluyen colegios, universidades y escuelas profesionales, e incluso los entonces nuevos medios de comunicación social (radio, televisión). Este decreto destaca el valor de la educación en la vida social, en línea de lo que dice el Concilio Vaticano II en Gravissimum Educationis, y renueva al papel del apostolado de la educación.

Reconoce las dudas que existen sobre este apostolado ("Hay entre nosotros quienes están convencidos de que los centros de educación de la Compañía en algunas partes del mundo resultan ya casi inútiles y que por lo mismo hay que dejarlos"), pero no impone una "solución uniforme". Más bien refuerza que nuestra Compañía "sienta con la Iglesia la peculiar importancia y eficacia del apostolado de la educación precisamente en nuestros tiempos" y dispone que los jesuitas "estimen mucho el apostolado educativo, como uno de los principales ministerios de la Compañía".

El problema de la integración de la tarea educativa en la misión de la Compañía está unido al de considerar la enseñanza de materias profanas como tarea propia de un sacerdote, es decir, el ejercicio de tareas que no son un ministerio directamente pastoral. Esto se resuelve en otro decreto, que trata sobre el apostolado sacerdotal: "Este ministerio sacerdotal comprende diversos oficios dentro de la unidad del Orden del presbiterado: la evangelización de los no creyentes, la catequesis, el ministerio parroquial o supraparroquial, la investigación y la enseñanza de las ciencias, la participación de la suerte y trabajo de los obreros y otras muchas obras apostólicas y ordenadas al apostolado" (Dec. 23, "Apostolado sacerdotal"). Es decir, la CG afir- 
ma que la enseñanza e investigación de materias profanas es una manera de ejercer el apostolado para un sacerdote de la Compañía.

El segundo decreto relacionado con el apostolado intelectual (Dec. 29, "Investigación científica") supuso la primera vez que se dedicaba un decreto a la cuestión de la investigación en una Congregación General. Dicho decreto estuvo provocado por el hecho de que hubo peticiones para que se dejara totalmente o se aminorase este campo de apostolado, en especial el de las ciencias positivas. Y, a su vez y de modo contrario, hubo peticiones que estimaban que este apostolado era indispensable y solicitaban una palabra de aliento para los que trabajaban en él, además de una intensificación general en el mismo. La CG mantuvo la importancia de este ministerio: "Aprecien en gran manera los jesuitas el trabajo científico, y en especial el de auténtica investigación, y considérenlo como uno de los ministerios de la Compañía más necesarios". Y se añaden algunas razones: "Es un apostolado muy eficaz, del todo conforme con la antigua tradición de la Compañía, y responde plenamente a las recomendaciones tantas veces reiteradas por los Sumos Pontífices, en particular durante el último siglo. Se adapta muy bien a las exigencias de los hombres de nuestro tiempo, pues constituye una excelente base para iniciar y continuar el diálogo, incluso con los no creyentes, y sirve de medio para ganar su confianza en la Iglesia y para elaborar y enseñarles a realizar la síntesis de la fe con la vida". Se da más importancia a las ciencias sagradas y a las que están más relacionadas con ellas, pero también se quiere decir lo mismo de las ciencias llamadas positivas.

Y dan un consejo concreto a los jesuitas destinados a este trabajo que requiere toda la persona: "entréguense a él con abnegación y fortaleza de ánimo" y "no se dejen llevar de la ilusión de poder servir mejor a Dios en otras ocupaciones al parecer más directamente pastorales".

Hubo un tercer decreto (Dec. 30, "Artes") también relacionado con el apostolado intelectual. En este breve decreto se ensalza la importancia del arte "para la edificación del Reino de Dios" y se busca "fomentar la actividad de los Nuestros que trabajan en este campo para la mayor gloria de Dios", así como su trabajo mutuo. Los jesuitas en formación han de incluir el mundo de las artes en su formación general para que "todos se preparen mejor al apostolado en la moderna sociedad".

\section{(B) Congregación General 32 (1975)}

La opción por "la fe y la justicia" fue el concepto estrella de esta CG (Dec. 4, “Nuestra misión hoy: servicio de la fe y promoción de la justicia"). Esta opción renueva la reformulación original del fin de la Compañía, que se centraba, ya en su formulación del siglo XVI, en la defensa de la fe, unida a la realización de obras de misericordia y al bien común. Una consecuencia no buscada de la CG 32 fue entender que el apostolado intelectual ya no tenía cabida en la misión de la Compañía. La "situación de injusticia" global, el "servicio de los pobres" y la cercanía a "los sin voz y los sin poder" parecían implicar un alejamiento del mundo intelectual. Este cuestionamiento o duda ha acompañado a la vida de la Compañía durante décadas.

Sin embargo, esta CG no solo tiene en cuenta directamente la cuestión intelectual ("un buen número de nuestros contemporáneos están fascinados, incluso dominados, por los poderes de la razón humana"), sino que sienta las bases para afirmar que el servicio a la fe y la promoción de la justicia están relacionados con una componente intelectual importante. Según la CG 32, en su decreto 4, el servicio a la fe pide el estudio de "los grandes problemas a los que la Iglesia y la Humanidad deben hoy hacer frente", la renovación de "las estructuras de la reflexión teológica" y "la búsqueda de un nuevo lenguaje, unos nuevos símbolos". Por otro lado, la promoción de la justicia invita a fijarnos en la injusticia de las estructuras vigentes, lo que lleva a pensar en su reforma con un estudio a fondo. Esto implica que "estemos dispuestos a consagrarnos a los estudios austeros y profundos que se requieren cada vez más para comprender y resolver los problemas contemporáneos".

La misma CG hace referencia a llegar a "los que tienen responsabilidad o influencia sobre las estructuras", a los que pueden ser "agentes de transformación social". Esto tiene que ver con la educación y es parte de la promoción de la justicia o del servicio a los pobres. Queda recalcada la mayor seriedad posible en cualquier actividad del jesuita. La dimensión intelectual se hace parte de nuestras preferencias apostólicas. Para esto hacen falta personas que se dediquen a la investigación y ciencia. Y muchas veces lo óptimo son las instituciones propias de educación superior o centros de enseñanza, revistas, etc.

\section{(C) Arrupe (1965-1983)}

Del magisterio del P. Arrupe podemos destacar un documento escrito en 1976 que lo dedica al papel del apostolado intelectual en el apostolado de la Compañía. En ese texto defiende que para hacer real "la dimensión intelectual inherente a nuestras opciones apostólicas preferenciales" ha de destinarse a 
un número significativo de jesuitas a trabajar "específicamente en tareas de investigación y ciencia y, en términos generales, en un apostolado explícitamente intelectual" (Arrupe, 1976).

El P. Arrupe lanza una descripción, más que una definición precisa, de lo que es apostolado intelectual: "Me refiero tanto al apostolado que se ejerce mediante actividades intelectuales como al apostolado entre los intelectuales. Pienso en nuestros profesionales de las ciencias, la investigación, la reflexión, la literatura o el arte, en los dedicados a tareas docentes o formativas, en nuestros publicistas, aun a nivel de vulgarización. Y cuando digo "intelectuales" aludo a los pensadores, investigadores, hombres de ciencia, a los profesionales de cualquier actividad típicamente intelectual" (Arrupe, 1976).

El servicio de la fe y la promoción de la justicia es el criterio prioritario también para la selección del área de apostolado intelectual a ser fomentada, pues no "cualquier tipo de quehacer intelectual o de investigación encaja de la misma manera en nuestra misión".

En dicha carta apunta a muchas cuestiones relacionadas con el apostolado intelectual. Entre ellas, pide mantener lo que hoy denominamos excelencia académica: "todo centro de estudios dirigido por la Compañía tiene la responsabilidad de mantenerse en un alto nivel no sólo docente, sino también de investigación, al menos en una especialidad cuidadosamente elegida". Por otro lado, apunta a un apostolado intelectual que sea también testimonio de pobreza, como "nuevo estilo de compromiso apostólico intelectual". Y también busca formas de asegurar la fidelidad a las motivaciones evangélicas y apostólicas en el compromiso intelectual, de sentirse hombres en misión integrados en el cuerpo de la Compañía, desde un equilibrio entre vida religiosa y sacerdotal y en fidelidad a la Iglesia que da la misión.

El mismo P. Arrupe recuerda una alocución de Pablo VI de 1974 en la que describe a la Compañía como un colectivo de "enviados de la Iglesia", y asocia a este envío "la investigación y la enseñanza teológicas... el apostolado de las publicaciones y ediciones... el apostolado social y la actividad intelectual y cultural que desde las escuelas para la formación integral abarca todos los grados de la formación universitaria y de la investigación científica". En esa misma alocución el Papa formuló una expresión que ha sido citada en otros contextos: "incluso en los campos más difíciles y de primera línea, en los cruces de las ideologías, en las trincheras sociales, donde ha habido o hay confron- tación entre las exigencias urgentes del hombre y el mensaje cristiano, allí han estado y están los jesuitas". Esta referencia no es exclusiva al apostolado intelectual, evidentemente; pero tiene en ella un puesto relevante (Pablo VI, 1974).

\section{(D) Congregación General 34 (1995)}

En la Congregación General 34 se dedican dos decretos al tema que nos ocupa. Uno de ellos es "Dimensión intelectual del apostolado de la Compañía de Jesús" (Decreto 16). En este decreto se reafirma "con vigor la singular importancia de la calidad intelectual de cada uno de nuestros ministerios". Se destacan el papel de la razón, la libertad y la inteligencia humanas. La eficacia de la evangelización pide "rigor en el conocimiento, respeto hacia los demás en el diálogo intercultural y análisis crítico" e implica no rechazar "la legítima autonomía de la ciencia” (Gaudium et Spes, 36).

La dimensión intelectual es una invitación a vivir en "verdadera comunión con los demás", pues implica una "capacidad humilde para aceptar las alabanzas y afrontar los rechazos y las polémicas". Supone adquirir la capacidad de vivir una "tensión creativa" entre actitudes abiertas y críticas entre culturas y confesiones. El texto recuerda que en la tradición eclesial la "lectura de los signos de los tiempos" implica reflexión teológica, análisis social y discernimiento. Ser servidores de la Palabra y discernir la presencia y actividad de Dios hacen necesarias tanto las ciencias sagradas, como la teología católica, como las disciplinas profanas, como la filosofía, el análisis social y las ciencias naturales.

El siguiente decreto de la CG 34 a presentar aquí es "La Compañía y la vida universitaria" (Decreto 17). Está principalmente dedicado a las casi doscientas instituciones de educación superior de la Compañía de Jesús. Es consciente del desafío de la estructura de las instituciones. Profundiza en dos conceptos que desde entonces se han utilizado mucho para reflexionar sobre las universidades jesuitas: el sustantivo "universidad" y el adjetivo "jesuítica". El sustantivo habla de los objetivos "propios" de toda universidad (docencia, investigación, servicio a la sociedad), que incluyen autonomía, integridad, serena investigación y abierta discusión de la verdad.

Y a la vez profundiza en el adjetivo "jesuítica" que implica la participación en la "identidad y misión fundamentales de la Compañía". Se quiere evitar instrumentalizar la universidad, pero se quiere a la vez afirmar la necesidad de interrogarnos de continuo sobre "el para qué del conocimiento" y pensar en cómo se 
armoniza la institución con el encuentro de "la fe que obra la justicia" y "los fines que la Compañía aspira lograr en ella".

\section{(E) Kolvenbach (1983-2008)}

La preocupación por la universidad ha estado presente en los casi 25 años de generalato del P. Kolvenbach. Ha recogido lo que quedaba de "resabios antiuniversitarios e incluso antiintelectuales" en la Compañía para traducirlo en "aceptación generalizada de la universidad como privilegiado instrumento cultural y apostólico" (Agúndez Agúndez, 2008). En recuerdo de los mártires de El Salvador (1989) el P. Kolvenbach destacó que una universidad puede ser un instrumento de justicia inspirada en el evangelio. Ignacio Ellacuría, desde la UCA de El Salvador, realizó dos aportes importantes en lo que respecta a la universidad en general y a la universidad jesuita en particular: por un lado, teorizó sobre la necesidad de poner la universidad al servicio de los intereses de las mayorías populares y del conocimiento de la realidad nacional; por otro, hizo que la institución que él lideraba se transformara según esos ideales (Ellacuría, 2012).

Se ha designado como "modelo Ledesma-Kolvenbach" a la traducción en lenguaje moderno lo que en latín el P. Ledesma en el siglo XVI definió como los cuatro fines de la universidad jesuita: utilitas, iustitia, humanitas, fides. El mismo P. Kolvenbach, en numerosos discursos, describió estos conceptos y su aplicación para la universidad jesuita contemporánea. Además, profundizó en cuestiones que alimentan muy directamente la vida de una universidad jesuítica: el carisma original o impulso fundacional de dichas instituciones, el papel del saber, la conciencia crítica, la excelencia, la relación eclesial, la evangelización de la cultura, los valores, la interdisciplinariedad, la pedagogía, etc.

\section{(F) Nicolás (2008-2016)}

El P. Nicolás también ha tenido intervenciones con el objeto de inspirar la identidad y misión jesuíticas de las universidades. Ha hecho dos convocatorias para todos los rectores y responsables de las universidades de la Compañía (México, 2010; Australia, 2015). En sus textos destacan los conceptos de profundidad, universalidad y creatividad, como pautas de renovación (Nicolás, 2010).

En el año 2014 ha escrito un texto inédito sobre renovación de instituciones jesuitas (no solo universidades) en línea de lo apuntado en la CG 34 en hacer que la universidad, como institución, aporte a la misión jesuita en su conjunto, en vez de tener una vida independiente (Las instituciones apostólicas al servicio de la misión). También ha escrito un texto para los jesuitas en el que resalta el papel de la investigación como aporte de los propios jesuitas, más allá de otras tareas que de hecho son más frecuentes como pueden ser la gestión o la pastoral (Sobre los jesuitas destinados al apostolado intelectual).

Entre los aportes del tiempo del generalato del P. Nicolás a la inspiración propia de la universidad jesuita es de destacar la publicación de un número de la revista Promotio Iustitiae, editado por el P. Patxi Álvarez de los Mozos SJ, consagrado al tema de la promoción de la justicia en las universidades jesuitas. En este extenso documento, contrastado por una treintena de personas con responsabilidad en universidades jesuitas de todo el mundo, se estudia la razón de ser de las universidades de la Compañía hoy y su necesaria orientación hacia la justicia. Se analizan cuatro dimensiones de las instituciones universitarias para las cuales se plantean retos concretos y se ponen ejemplos de buenas prácticas en cada uno de dichos ámbitos: la formación del alumnado, la investigación universitaria, la proyección social y la comunidad universitaria (Álvarez, 2014).

En estos años se han multiplicado las revistas académicas, las investigaciones y tesis doctorales sobre le función y gestión de las universidades. También sobre las universidades jesuitas han crecido los estudios. Podemos citar aquí la tesis doctoral de B. Vivanco como ejemplo de estudio centrado en la fundamentación y la búsqueda de buenas prácticas relacionadas con la promoción de la justicia en las universidades jesuitas, con una amplia encuesta sobre la opinión de los que trabajan en una decena de universidades jesuitas españolas (Vivanco, 2013).

\section{(G) Sosa (2016-...)}

Cuando estamos terminando de redactar este artículo, el P. Arturo Sosa ha sido elegido prepósito general de la Compañía de Jesús, en la CG 36 (octubre de 2016). Evidentemente aún no ha tenido pronunciamientos oficiales sobre el apostolado universitario. Sin embargo, alguna consideración sí se puede realizar al respecto. Por un lado, es un jesuita que proviene del mundo universitario. En su vida apostólica ha unido la reflexión intelectual con la acción social.

Además, en su primera homilía como superior general, con ocasión de la celebración de la acción de gracias por su elección, hizo referencia explícita a la necesidad de una "extraordinaria profundidad inte- 
lectual para pensar creativamente" los modos en que el servicio a la misión puede ser más eficaz, desde el magis ignaciano. Pide "pensar en profundidad" las alternativas para superar "la pobreza, la inequidad y la opresión". En su siguiente homilía pública, en la eucaristía de la clausura de la CG 36, afirmó que "Nuestro apostolado es necesariamente intelectual". Se refiere a unir el discernimiento, la fe y la apertura del corazón a la acción del Espíritu Santo, con la comprensión sobre cómo está el mundo y cómo es la vida de los distintos pueblos.

\section{EL LIDERAZGO IGNACIANO COMO NUEVO PARADIG- MA DE RENOVACIÓN DE INSTITUCIONES JESUÍTICAS}

En este segundo apartado del presente trabajo entramos ya a definir el liderazgo ignaciano y sus valores. En la primera parte presentamos algunas teorías de liderazgo como concepto genérico. Comprobaremos que hay sus diferencias y que algunas definiciones son más compatibles que otras con el ideal ignaciano. Después recordaremos que si el liderazgo es ignaciano, estamos diciendo que nos basamos en la historia y experiencia de una persona concreta: san Ignacio de Loyola. Por último, describiremos algunas características de dicho liderazgo según las Constituciones de los jesuitas y la experiencia vivida.

\section{(A) El liderazgo como concepto estudiado}

El liderazgo como hecho social y organizacional se ha estudiado con cierta sistematicidad desde hace más de un siglo. En las últimas décadas se han multiplicado los estudios sobre el liderazgo. La investigación en esta área de comportamiento humano ha permitido avanzar y realizar nuevas formulaciones. En los siguientes párrafos se resumen algunas teorías de liderazgo (Guibert, 2014a):

\section{Rasgos}

Según esta teoría los "grandes hombres", personas extraordinarias, tenían algunos rasgos heredados particulares. El decir, el liderazgo es algo innato y heredado, no aprendido. Dichos rasgos son: energía, visión de futuro, inteligencia, capacidad de influencia y de buena relación con colaboradores, buena respuesta al estrés, capacidad de dar respuesta a demandas externas, etc.

Esta teoría dominó hasta mediados del siglo XX, pero luego fue juzgada como simplista. El liderazgo depende del contexto social. La teoría de rasgos heredados no es suficiente para explicar el liderazgo.

\section{Transacción}

El liderazgo transaccional busca que las personas cumplan con su misión a base de premios y castigos, según el esfuerzo y el desempeño realizado. Así se compra la lealtad. En un concepto centrado en la tarea, más que en las personas. Tiene como objetivo supervisar y organizar tareas y resultados, buscando faltas y errores y premiando lo que está bien. Atiende el propio interés de los trabajadores (sus necesidades básicas de satisfacción) con motivaciones externas (premio y castigo).

Se centra en los procesos existentes. No busca cambiar el futuro o llegar a nuevas ideas o cambiar la cultura o finalidades de la organización. Se busca premiar a los seguidores y mantener el status quo.

\section{Transformación}

El liderazgo transformacional busca mejorar la motivación de los colaboradores. Quiere cambiar a las personas, tocando sus valores morales, creencias, ideales, expectativas y aspiraciones (más arriba en la escala de Maslow). Busca un desarrollo personal, despertar las conciencias.

El líder se implica personalmente, da apoyos personales. Su ejemplo es importante. Ha de generar ilusión y convencimiento. Se atiende a la persona entera, no a un mero empleado. Se fomentan cambios de actitudes, ideas nuevas y no convencionales (Bass). Se da más confianza, se hace participar en temas importantes de la organización. Se invita a cambiar la cultura organizativa y su status quo. Implica ir más allá de los intereses personales e ir a favor de la organización.

\section{Resonancia}

El liderazgo tiene una dimensión emocional. La inteligencia emocional estudia las reacciones emocionales y su correcta gestión. Gestionar los propios sentimientos y la relación con otras personas es importante, no solo el nivel intelectual.

El líder promueve sentimientos positivos en sus seguidores. Producir resonancia es sintonizar con las emociones de los colaboradores y promover sentimientos positivos, en vez de reacciones emocionales negativas (resentimiento, tristeza, ansiedad, ...). Eso mejora el rendimiento de las personas. Supone transparencia y expresar los propios valores con sinceridad (Goleman, Boyatzis y McKee, 2002). 


\section{Adaptación}

Este modo de liderar distingue entre retos técnicos y retos adaptativos. Para un problema "técnico" las autoridades formales aplican criterios bien conocidos sobre el problema. Existe un conocimiento (dentro o fuera de la organización) y un experto lo aplica. El problema "adaptativo" es más complejo. El conocimiento no es un dato, hay que generarlo. Los implicados en el problema son parte de la solución. Sus creencias, conductas, valores y esquemas mentales, han de adaptarse y cambiar.

El líder no es el que sabe la solución y la aplica. Ha de identificar el reto adaptativo y hacer las preguntas adecuadas. No puede negar la realidad. No ha de buscar un chivo expiatorio o un enemigo fuera de la organización. No hay un mapa con un camino a recorrer ya conocido. Las soluciones hay que buscarlas o crearlas. Hace falta mucha conversación e implicación de todos, deseo de aprender y de responsabilizarse (Heifetz y Linsky, 2009).

\section{Variables}

Más allá de esas teorías concretas que se basan en una idea o concepto puntual o único, aunque en sí sean ilustrativas, los estudios contemporáneos de liderazgo analizan bloques o conjuntos de variables distintas que se estiman importantes a la hora de definir a una persona líder. Estas variables se toman a la vez de distintas teorías de liderazgo, de manera un tanto ecléctica. Y se logran así, tras el análisis simultáneo de distintas variables, unas descripciones bastante completas de las realidades a analizar.

Una manera de realizar un análisis puede ser fijarse en características de estilo ejecutivo. Estas pueden ser: orientación a las personas o a las tareas, centralización o participación en la toma de decisiones, ámbito de comunicación preferido, orientación al horizonte a corto o a largo de la acción. Se puede analizar también la orientación al logro (la motivación por empresas retadoras y difíciles), al poder (ejercer influencia, ser influyentes, hacer prevalecer sus ideas) o a la afiliación (tener relaciones amigables, interactuar positivamente). Los estudiosos pueden también fijarse en características psicológicas que tienen un impacto importante en el estilo de liderazgo: el grado de emocionalidad, el estilo cognitivo (intuitivo o analítico) o la tolerancia a la ambigüedad. Todas estas variables citadas en este párrafo están tomadas, a modo de ejemplo, de un reciente libro de J.L. Álvarez en el que se estudia la personalidad y el liderazgo de los últimos presidentes de gobierno españoles (Álvarez, 2014).

\section{(B) Lo ignaciano como experiencia vivida}

Si a algo denominamos ignaciano es porque lo queremos asociar a la experiencia de Ignacio de Loyola (Azpeitia, 1491 - Roma, 1556) o a la interpretación que hagamos de su vida y obra (Ruiz Jurado, 2014). Los principales legados de san Ignacio pueden resumirse en dos: la creación de la Compañía de Jesús y la fundación del carisma ignaciano. Lo primero tiene que ver con la orden religiosa que él fundó en su afán de "ayudar a las ánimas" de manera estructurada, con un grupo de compañeros o "amigos en el Señor". Lo segundo tiene que ver principalmente con una experiencia espiritual, experiencia suya personal, que él describió en el libro de los Ejercicios Espirituales, y que transmitió a muchas personas.

La experiencia que se propone en los Ejercicios Espirituales, de hace cinco siglos, hace referencia a una experiencia espiritual personal y a un camino de conversión y compromiso con la realidad que uno vive. Son un camino de encuentro con Dios y una ayuda para tomar decisiones en la vida, decisiones que implican a la persona existencialmente. Supone personalizar la experiencia de Dios, encontrarse con el Señor, sentir lo que viene de Dios y seguir los impulsos que surgen en esa experiencia. Buscan sentir internamente el amor y la misericordia Dios. Buscan profundizar en la propia vocación y los discernimientos personales sobre aquello que uno cree que Dios le pide. Más que un curso de teología o un manual de doctrina cristiana, es una escuela de experiencia, de afecto y de lectura de sentimientos propios. Se proponen unas materias de oración, un método, una forma de acompañar, una manera de examinar y un modo de discernir lo que el Señor quiere de uno.

Mientras la experiencia de dichos Ejercicios Espirituales es primariamente personal o individual, hay otros textos de san Ignacio en los que busca algo más y que podemos asociar directamente al liderazgo. Otros textos de san Ignacio, como las Constituciones de la Compañía de Jesús o las Cartas, son fruto de ese mismo espíritu ignaciano que podemos descubrir en los Ejercicios Espirituales, pero tienen algo más. Ese "algo más" consiste en lo que podemos considerar clave en el liderazgo: personas y misión. Cómo acompañar a otras personas en el desarrollo de una misión conjunta. Cómo cuidar unas relaciones personales con vistas a una misión que implica a todos. Cómo hacer atractiva una misión, explicarla y aplicarla a distintos contextos y áreas de la vida. 
En las Constituciones san Ignacio habla a los jesuitas, los que son parte de la Compañía de Jesús o van a serlo. Organiza un grupo humano y busca el modo en que todo el cuerpo que está creando se disponga a escuchar a Dios y cumplir su voluntad. Se pasa de una experiencia personal íntima a una experiencia corporativa. Ahí hay elementos claros de liderazgo. En este caso, al dirigirse a jesuitas vinculados entre sí con un voto de obediencia, la pertenencia a la orden marca unas características propias de liderazgo.

Pero no es difícil aplicar ese modo de liderazgo en otras situaciones también ignacianas, pero no jesuíticas. Es decir, si denominamos "jesuítico" a lo referente a la orden de los jesuitas, podemos denominar "ignaciano" a lo que se inspira en san Ignacio pero no se refiere a los jesuitas, sino que hace referencia a laicos y laicas o a religiosas que se inspiran en san Ignacio. Por eso lo "ignaciano" va más allá de los mismos jesuitas. El carisma y modo de proceder de san Ignacio es un don para la Iglesia y muchas personas en la historia han seguido sus intuiciones y se han inspirado en su modo de vivir. Ya en tiempos de san Ignacio, los mismos Ejercicios Espirituales fueron propuestos más a personas laicas que a jesuitas. En lo que respecta a las Constituciones, aunque sea un libro de jesuitas para jesuitas, hay también intuiciones muy válidas para otras situaciones de liderazgo.

Por otro lado, en sus más de siete mil Cartas, san Ignacio escribe a personas de perfiles muy variados. Podemos aprender aquí cómo trataba a las personas y cómo las acompañaba en el desarrollo de su misión. Plantea muchas situaciones apostólicas de muy diverso tipo. Si miramos algunas de las cartas con ojos actuales, podemos destilar en un buen número de ellas características de lo que hoy denominamos planificación estratégica, despliegue de objetivos o monitorización de los mismos. Se trata a veces de auténticas empresas apostólicas, a realizarse en distintos lugares del mundo, y en donde hay medios y fines, objetivos y metas, recursos y procesos, etc. No solo planifica tareas sino que muchas veces acompaña a los que hoy denominaríamos líderes o agentes multiplicadores, cuidándoles, inspirándoles, dándoles una visión, motivándoles y animándoles en las dificultades. Todo ello desde una experiencia espiritual (ver a Dios en todo, entregarse a los demás, etc.). Pero, además de la experiencia espiritual, en mucha de la correspondencia epistolar aparece una responsabilidad de guiar y acompañar a otras terceras personas.

En resumen, la vida de san Ignacio, con sus Ejercicios Espirituales, no es solo un ejemplo de cómo renovar uno la vida íntima espiritual y encontrar a Dios en su camino personal. Esa misma vida de san Ignacio, con sus Constituciones y Cartas, es también un ejemplo inspirador de cómo atender a otras personas en su misión, de cómo liderar con unas características propias.

\section{(C) La persona ignaciana líder}

Establecido el marco en el que se contextualiza que podemos hablar de un liderazgo ignaciano, toca ahora describir en qué consiste. Hay un texto muy concreto, la parte novena de las Constituciones, en el que se retrata el perfil del que haya de ser superior general de los jesuitas (Constituciones, nn. 723-735). Ahí aparecen rasgos muy determinados. Algunos parecen directamente orientados a la tarea de liderar. Otros parecen más centrados en la propia vocación jesuita. Algunos de dichos rasgos son los que siguen (Guibert, 2014b):

- Muy unido a Dios y familiar en la oración y todas sus operaciones. El primer rasgo tiene que ver con la experiencia de Dios. Es experiencia vivida, no teórica sin más. Y es experiencia que afecta a toda la vida, no en sentido temporal, sino en sentido de amplitud de todas las dimensiones de la vida. Si en los Ejercicios se propone una experiencia de Dios, haber pasado por ese proceso es el primer elemento de nuestro listado. Y además es de suponer que se ha de haber pasado por el proceso con cierta profundidad (de ahí el "muy unido") y habiendo sido afectado personalmente de manera global por el mismo (de ahí el "todas sus operaciones"). La experiencia de Dios no es algo extrínseco a la persona. Se supone que alimenta, ilusiona e inspira todo lo que hacemos y somos. Vivir esto es lo primero que se busca en un líder ignaciano.

- Ejemplo en virtudes. Unido a lo anterior aparece un segundo rasgo sobre el que se pueden hacer dos comentarios. Por un lado, se nos recuerda que el ejemplo y el testimonio es lo que nos hace creíbles, es lo que tiene capacidad de persuadir y motivar, más que las palabras bonitas. Por otro lado, prácticamente se asocia la experiencia de Dios a las virtudes. Es decir, la experiencia de Dios busca cambiar a uno y mejorar en el servicio, no es una experiencia íntima que no afecta a la propia realidad; nos afecta en que cuanto que es una ayuda para ser y servir mejor.

- Probado, libre ante pasiones internas. Para tener un puesto de responsabilidad hacia otras personas, con la posibilidad de influir en posi- 
tivo pero también en negativo, ante el riesgo de poder hacer daño personalmente, es bueno haber tenido experiencias de "probación" que hagan a uno caer en la cuenta de cómo es, reconociendo sus puntos fuertes y débiles, aciertos y errores cometidos. La vida es una prueba continua que nos enseña a conocernos y a conocer a los demás. Unido a esto, uno ha de ir despojándose de "pasiones desordenadas" como pueden ser el deseo de brillar o triunfar o poseer, o también, por otro lado, el tener miedos o querer seguridad a toda costa o ser excesivamente conservador. La experiencia de la vida, su examen, la madurez, el conocimiento de uno mismo, son requisitos necesarios para ayudar a otras personas en lo personal.

- Fuerte, magnánimo, perseverante; con ánimo. En la relación humana hay momentos difíciles. La vida no es fácil. Hay mucho sufrimiento. Toca a veces perseverar en las opciones buenas y tener cierta fuerza interior y ánimo. Previamente, uno ha de haber encontrado, en Dios, en uno mismo y en otros, esa fuerza y ánimo que luego ha de transmitir. Ser referente para otros implica haber encontrado previamente la roca y motivación que primero es referencia para uno.

- Recto y severo, combinado con benigno y manso. Saber conjugar distintos roles según sean las circunstancias es un arte. No solo severidad, no solo mansedumbre. En distintas circunstancias hay que adoptar distintas posturas. Hay que tener la lucidez suficiente para caer en la cuenta de cuándo conviene tener una u otra postura. Dependerá de la situación en la que se encuentre tu interlocutor. Puede aplicarse aquí el dicho que se atribuye a Aristóteles: "Cualquiera puede enfadarse, eso es algo muy sencillo. Pero enfadarse con la persona adecuada, en el grado exacto, en el momento oportuno, con el propósito justo y del modo correcto, eso, ciertamente, no resulta tan sencillo".

- Compasivo. La capacidad de estar afectivamente cerca de las personas, de entenderlas, de situarte en sus problemas y deseos, es una virtud necesaria. En un líder no buscamos solo ideas o posturas acertadas. Buscamos una persona en quien confiar, que nos entienda, que sintamos cerca, que veamos que capta nuestra situación, que resuena con lo que internamente vivimos. El líder, entonces, sale de sí mismo y se sitúa en lo que siente vitalmente la otra persona.
- Con gran entendimiento, con buenas letras. Ignacio tuvo en estima el estudiar y el formarse para entender la realidad que quería atender. Creía en el valor del intelecto para ayudar a resolver problemas. Dedicó mucho tiempo a estudiar y formarse. La apertura de mente, la visión y los conocimientos son ayudas en el liderazgo. Pero esto es sólo una característica más dentro de un conjunto más amplio.

- Con juicio, prudencia, con capacidad de discernimiento y experiencia en vida espiritual. Una de las palabras clave en la espiritualidad ignaciana es el "discernimiento". Es un método o actitud que invita a relativizarlo todo para llegar al fin que se pretende, fin que unimos a la voluntad de Dios. Y no solamente relativizar cosas para sentirse libre ante todo, para no perder la paz, sino para mejor acertar en juzgar y valorar adecuadamente lo que se ha de hacer. La vida espiritual es un camino de despojo. Pero no un despojo para aislarse del mundo y escaparse de los problemas. Es más bien un despojo para volver a vestirse y optar en cada paso por lo que sea más apropiado. Discernir es optar, tomar decisiones, implicarse existencialmente en las cosas. Cuidar las formas de discernimiento y las decisiones que se toman es clave. Acompañar a otros en estos procesos es tarea de un líder.

- Verdaderamente humilde. La humildad es uno de los rasgos que más aparecen en la vida de san Ignacio. La manera de vencer a los apegos del mundo, la riqueza, la imagen, el honor, etc. es abajarse y humillarse y ponerse en el lugar del último. La única manera de sentir lo que siente una persona humillada es pasar uno por un proceso así. Y así uno cultiva una sensibilidad de respeto a los más necesitados y sufrientes y el discernimiento puede ser auténtico y no un autoengaño o proceso de legitimación de algo desordenado o no bueno. La tentación de buscar la gloria vana y la seguridad de la riqueza o del bienestar material nos acompaña durante toda la vida. Buscar la humildad, solidarizarse con el último, preferir los últimos puestos, desear acercarse a sentir lo que siente el humillado es la única manera de no caer en la tentación del arribismo o no buscarse más a uno mismo, en vez de servir a la misión encomendada.

- De mucha bondad y amor a la Compañía. Si las características anteriores resultan demasiado di- 
fíciles o idealizadas, el último rasgo que plantea san Ignacio es más sencillo en expresión, pero más profundo en vivencia: bondad y amor. Eso quiere decir que en un líder se busca bondad como primera característica. No habilidades de gestión o habilidades sociales. Se entiende que una experiencia espiritual sana se traduce en bondad y amor. Esa es la principal vivencia a buscar en la persona líder. Amar a la causa, a la misión, a las personas implicadas, es la fuerza más poderosa que activa en un líder otros mecanismos internos para mejorar en el servicio.

\section{(D) Un liderazgo para una misión}

El liderazgo ignaciano no termina sin más en las características de la persona líder que se han señalado hasta ahora, a partir del texto citado de las Constituciones de san Ignacio. Lo que se ha descrito en el apartado anterior es para ser vivido en un contexto, un equipo y una misión.

El contexto en que se aplica el liderazgo ignaciano es casi siempre distinto al de una orden religiosa. Es decir, hay que buscar cómo traducir las características que se señalan aquí (las que se indican para el líder de los jesuitas en su tarea de liderar jesuitas) a un contexto laico y muchas veces agnóstico. Un contexto marcado por unas instituciones que tienen sus propios fines y que están establecidas en un ordenamiento jurídico. Es toda una tarea realizar esa traducción y buscar que la inspiración ignaciana se pueda encarnar en instituciones de distinto tipo.

Esas intuiciones ignacianas tienen también consecuencias para el otro polo de la relación de liderazgo, es decir para las personas lideradas. En el estilo ignaciano se buscará que los liderados asuman su responsabilidad en la misión, que se sientan en servicio, que estén unidos y cuiden el clima de trabajo y su relación, que vivan de manera incipiente los valores del Reino que se quieren transmitir, que practiquen formas de discernimiento en común, que sepan manejar los conflictos, que tengan espacios de convivencia, de crecimiento y de formación, etc. (Guibert, 2014b).

La relación entre la persona líder y los liderados se puede describir con dos expresiones de la tradición ignaciana: cura personalis y cura apostolica. La primera expresión hace referencia al cuidado activo de la persona. Por un lado, se trata de la atención a su situación personal y su desarrollo; cuidar lo que le hace daño y promover lo que le ayuda. No somos piezas dentro de un organigrama. Somos personas con nuestras necesidades y deseos. Más que un perfil adminis- trador o gestor o dedicado a tareas, estamos ante una atención a la personas en cuanto tal. Ese desarrollo de la persona, en clave cristiana, lleva a las cuestiones de sentido que le afectan y a su encuentro con Dios, a que tenga una auténtica experiencia del Dios de la vida, a que Dios y la persona se encuentren.

Por otro lado, la expresión cura apostolica complementa a la anterior. Supone el liderazgo de la dimensión apostólica de las personas. El fin de la Compañía de Jesús no es la realización personal íntima de los jesuitas mismos, sino la ayuda que por medio de ellos se realiza a las personas a las que se sirve. De manera análoga, una tarea del líder es integrar al liderado en una misión, hacer que salga de sí mismo y se centre en la misión común, más allá de sentirse cuidado sin más. El reto es preparar a los liderados para que sirvan más allá de sus necesidades personales y sus visiones particulares, haciendo suyas las prioridades de la misión.

Todo lo anterior, la tarea de liderazgo y la relación entre el líder y los liderados, tiene lugar para un fin concreto: una misión que envuelve y seduce a unos y otros. El liderazgo busca que unas personas lideradas se orienten a una misión, por influencia de una persona líder. La misión no es algo neutral en el caso ignaciano. Tiene ciertamente que ver con el Reino de Dios y se vive en un contexto eclesial. En el caso jesuítico es una misión con rasgos típicos: una fe que promueve la justicia, en diálogo con las religiones y culturas. Todas las instituciones jesuitas, todos los campos de apostolado y acción, buscan encarnar estos rasgos de misión en formas variadas.

En el caso de una institución universitaria esa misión tiene también unas traducciones concretas. A modo de ejemplo podemos fijarnos en lo que Juan Pablo II, en Ex Corde Ecclesiae (n. 32), decía hace un cuarto de siglo respecto a las universidades católicas: "Sus actividades de investigación incluirán, por tanto, el estudio de los graves problemas contemporáneos, tales como, la dignidad de la vida humana, la promoción de la justicia para todos, la calidad de vida personal y familiar, la protección de la naturaleza, la búsqueda de la paz y de la estabilidad política, una distribución más equitativa de los recursos del mundo y un nuevo ordenamiento económico y político que sirva mejor a la comunidad humana a nivel nacional e internacional" (Juan Pablo II, 1990).

Es decir, nada es neutro. La misión marca unas líneas de trabajo. En este caso la Iglesia marca unas líneas de trabajo que la Compañía asume y formula desde su carisma. El líder, según el tipo de institución, 
piensa en las personas adecuadas para llevar adelante esa misión. Las personas y el estilo son también parte del mensaje. No se pueden separar la persona líder y sus valores, la relación con los liderados y sus modos de proceder, y la misión. Son tres vértices (líder, personas, misión) que se relacionan entre ellos. Son tres focos de atención a la hora de mejorar el servicio que se hace.

\section{LIDERAZGO IGNACIANO EN LAS CONGREGACIONES GENERALES}

Como tercer apartado sobre el liderazgo ignaciano y las instituciones jesuitas, podemos hacer una referencia a lo que se señala en las últimas congregaciones generales sobre el término que aquí estudiamos.

Como es sabido, el término "liderazgo" no es un término de la tradición jesuita. Siempre se ha hablado más de "gobierno". Como todos los términos nuevos, al principio genera cierto rechazo, en este caso quizá por tener algunas connotaciones empresariales y no explícitamente religiosas. Pero poco a poco se ha ido introduciendo en el lenguaje jesuítico oficial (Guibert, 2014b).

\section{(A) Congregación General 34 (1995)}

El término "liderazgo" no está en las Constituciones originales de la Compañía de Jesús (siglo XVI), ni en las Normas Complementarias que aprobó la CG 34. Pero sí aparece en algunos textos de la misma CG 34.

Hay tres referencias explícitas. Una se refiere al "liderazgo laico en las obras de la Compañía". Sobre esto se habla cuando se reflexiona sobre la colaboración con los laicos en la misión y en algunas referencias a las obras apostólicas: "Los laicos asumirán con todo derecho un papel de mayor responsabilidad y liderazgo en esas obras". Una segunda mención aparece al reflexionar sobre la posición de la Compañía de Jesús ante la situación de la mujer en la Iglesia y en la sociedad. Ahí se señala que "Agradecemos a las mujeres su liderazgo pasado y presente". La tercera mención se da el decreto sobre el ministerio de las parroquias. Se asocia el liderazgo con la participación que es promovida desde las parroquias: "[la parroquia] promueve oportunidades para la participación y el liderazgo laicales".

En resumen, aparece el término "liderazgo" asociado al laicado, no a los jesuitas. Para los jesuitas, se seguía utilizando términos más clásicos, como son obediencia, superior, o comunidad. Hay que esperar a la siguiente CG para que nuestro término se asocie al gobierno mismo de la Compañía.

\section{(B) Congregación General 35 (2008)}

En la CG 35 el término liderazgo aparece con más peso en los textos oficiales. En la comisión preparatoria, que analizó los postulados previos recibidos, se hacía una propuesta para la nueva CG que incluía la elaboración de cinco decretos. Uno de ellos era sobre "liderazgo y gobierno" (los otros temas eran: identidad y carisma; misión; colaboración con otros; obediencia).

Estas preocupaciones previas desembocaron en la creación y aprobación de un decreto que incluye de manera explícita cuestiones relacionadas con el liderazgo: el decreto 5, que se denominó "Gobierno al servicio de la misión universal".

En este decreto se pueden observar tres partes principales, dedicadas a distintos niveles de la tarea de gobierno: gobierno general, gobierno provincial, gobierno local. En los tres niveles se emplea el término "liderazgo". Se une la tarea del presidente la conferencia de superiores mayores con el "liderazgo apostólico". En la referencia a las comunidades de jesuitas, se recuerda que el superior local tiene el compromiso de "liderar a su comunidad según una vida comunitaria jesuita". Al mencionar el gobierno provincial y las exigencias del ministerio de gobierno se mencionan los cursos "para la formación en liderazgo", que incluye áreas como: principios de liderazgo en general, principios de gobierno ignaciano, trabajo en equipo, destrezas de gestión o destrezas para ser un miembro eficaz en un consejo de dirección.

En la misma CG 35 podemos encontrar dos referencias explícitas más al liderazgo en otros decretos. Son parte del análisis de las obras apostólicas: “¿Qué hace que una obra sea jesuita, y cómo puede ser sostenida por un liderazgo no jesuita?". Por otro lado: "El liderazgo de una obra jesuita depende del compromiso con la misión y puede ser ejercido por jesuitas o por otros". Se trata de un tema, las obras apostólicas, para las que se marca una línea de renovación desafiante.

\section{(C) Congregación General 36 (2016)}

Esta CG continuó con la senda presentada en la CG 35 en lo que respecta al gobierno. Aprobó el decreto "Gobierno renovado para una misión renovada". Este decreto avanzó en la reflexión de la CG anterior sobre este tema. Sienta las bases de las características propias del gobierno de la institución: "el gobierno en la Compañía es personal, espiritual y apostólico".

La CG quiere realizar un aporte específico a la cuestión del gobierno destacando tres perspectivas (discernimiento, colaboración y trabajo en red) que conviene 
destacar en la definición del modo de proceder de la Compañía: "El liderazgo apostólico del superior local está hoy marcado por la importancia del discernimiento, la promoción de la colaboración y el trabajo en red".

El discernimiento es el esfuerzo de unirnos a los diseños de Dios y sienta la base espiritual para la planificación apostólica. Es algo crítico hoy en día en un contexto de complejidad creciente de la misión y de reducción del número de jesuitas. La colaboración, término ya destacado también por las CG 34 y 35 , es decisiva para la viabilidad de la misión y es parte de nuestra identidad como miembros de la Iglesia. El trabajo en red, por su parte, fomentado por el desarrollo de las tecnologías de comunicación, es una nueva realidad ya existente. Las redes dependen de personas capaces de "aportar visión y liderazgo para una misión en colaboración".

Al relacionar la realidad de 2016 (CG 36) con la de 2008 (CG 35) uno de los puntos en donde se destacan avances es en la creación y establecimiento de "programas de desarrollo de liderazgo". Son peticiones que se hicieron en la CG 35 y que se han ido llevando a cabo en un contexto de colaboración entre jesuitas y colaboradores. La formación para el liderazgo se sigue manteniendo como una recomendación. Esto es parte del conjunto de las recomendaciones sobre el gobierno y, de modo particular, del liderazgo de las comunidades jesuitas locales y de los nuevos retos del liderazgo laical en los ministerios jesuitas.

\section{EL LIDERAZGO IGNACIANO COMO OPORTUNIDAD EN EL GOBIERNO DE LAS UNIVERSIDADES JESUITAS}

El análisis realizado en este artículo nos sitúa en dos de las dimensiones clave del modo de proceder jesuítico de las instituciones de educación superior de la Compañía de Jesús: gobierno y liderazgo. El enfoque utilizado para estudiar cada una de las dimensiones ha sido distinto, pero tienen en común su relevancia para la inspiración carismática de dichas instituciones.

Los casi doscientos centros de educación superior tienen una vida propia en general muy rica y variada. En estas décadas han cambiado muchos de ellos en su estructura. Han encarnado valores propiamente universitarios de manera más decidida. También han sido muy creativos a la hora de encarnar universitariamente las intuiciones propias del carisma ignaciano.

Por otro lado, las universidades han sido organizaciones muy autónomas. La Compañía interviene, por un lado, en los nombramientos de máximos responsables y en las aprobaciones de nuevas instituciones y en los asuntos legales y económicos, según los estatutos de cada institución. Por otro lado, en la inspiración carismática que alimenta cada una de las instituciones.

En esta época de cambio cultural, que afecta directamente a la Iglesia como entidad que trabaja los valores y las ideas, la Compañía ha buscado renovarse y actualizarse. En esa renovación ha entrado obviamente la actualización de los "por qués" de la educación e investigación jesuíticas. En el primer apartado de este artículo se ha pretendido hacer un recorrido somero por las principales preocupaciones y aportes que se han realizado en estas décadas desde el gobierno "ideológico" de la Compañía. De la preocupación por pensar que una apuesta explícita por la justicia desembocaba en que no tenía sentido la dedicación al apostolado intelectual en la Compañía se ha pasado a renovar el sentido de una universidad jesuítica y su entronque en la misión de la misma Compañía. Las grandes opciones de la misión jesuítica (fe, justicia, diálogo, inculturación, reconciliación) no solo no son ajenas a la vida universitaria sino que se realizan mejor y con más fruto con la implicación de las universidades jesuíticas.

Y para llevar adelante esta misión hacen falta personas. La inspiración del gobierno de la Compañía no es sólo ideológica en el sentido de apuntalar principios y conceptos que se quieren afirmar y hacer vigentes y en el sentido de buscar que las universidades los encarnen y alimenten. La actuación del gobierno de la Compañía tampoco es solo atender con delicadeza las cuestiones de decisiones sobre personas y nombramientos y sobre asuntos legales y económicos. Una nueva actuación del gobierno de la Compañía puede ser iluminar el servicio de liderazgo que se realiza y hay que realizar, porque éste afecta a las personas que asumen responsabilidades en el acompañar a otras en la consecución de una misión.

Fomentar el liderazgo ignaciano puede ser una nueva forma de intervención del gobierno de la Compañía. El valor de la persona, y en este caso de la persona líder, en cualquier institución es algo que no necesita justificación y menos en una institución jesuítica, en la que no producimos objetos sino que tratamos con personas y valores. El cuidar a esas personas líderes y darles instrumentos para que asuman su responsabilidad y la ejerzan con plenitud es un camino que promete fecundidad.

En la segunda parte de este artículo hemos analizado cuestiones de liderazgo en general y de liderazgo ignaciano en particular. Todas las instituciones se re- 
nuevan o están llamadas a ello. Las ciencias del comportamiento humano, la psicología, el comportamiento organizacional, las ciencias de la personalidad, etc. están también investigando y proponiendo nuevos conceptos y modelos de liderazgo. La tradición ignaciana encaja en algunas de estas teorías. Tiene una historia propia y unos valores que pueden renovar a las instituciones jesuitas y sus liderazgos.
Las universidades de todo el mundo se enfrentan a nuevos retos para servir universitariamente a las sociedades cambiantes de las que dependen. Las universidades jesuitas, desde su inspiración original y desde las reflexiones de estas últimas décadas, como se ha señalado en los párrafos anteriores, tienen un campo de renovación y profundización en su identidad y misión.

\section{BIBLIOGRAFÍA}

Agúndez Agúndez, M. (ed.). (2008). P. Peter-Hans Kolvenbach S.J. Discursos universitarios. Madrid: UNIJES.

Álvarez, J. L. (2014). Los presidentes espa ñoles. Personalidad y oportunidad, las claves del liderazgo político. Madrid: Lid.

Álvarez, P. (ed.). (2014). La Promoción de la Justicia en las Universidades de la Compañía", Promotio lustitiae, 116. [En línea]. Disponible en http://www.sjweb. info/documents/sjs/pj/docs_pdf/ PJ_116_ESP.pdf

Arrupe, P. (1976). El apostolado intelectual en la misión de la Compañía de hoy. Acta Romana, 16, pp. 1010-1023.

Bass, B. (1985). Leadership and performance beyond expectations. New York: The Free Press.

Concilio Vaticano II (1965). Constitución pastoral Gaudium et Spes sobre la Iglesia en el mundo actual Disponible en http://www.vatican.va/archive/hist_ councils/ii_vatican_council/documents/ vat-ii_const_19651207_gaudium-etspes_sp.html

Ellacuría, I. (2012). Universidad, derechos humanos y mayorías populares. En Senent, J. A. (ed.). La lucha por la Justicia. Selección de textos de Ignacio Ellacuría (1969-1989). Bilbao: Universidad de Deusto, pp. 303-316.

Goleman, D., Boyatzis, R. y McKee, A. (2002). El líder resonante crea más. Barcelona: Plaza y Janés.

Guibert, J. M. (2014a). Diccionario de liderazgo ignaciano. Bilbao: Mensajero.
Guibert, J. M. (2014b). Liderazgo ignaciano, ocasión de renovación en identidad y misión. Manresa, 86, pp. 317-328.

Heifetz, R. y Linsky, M. (2009). Liderazgo sin límites: manual de supervivencia para managers. Barcelona: Paidós.

Juan Pablo II (1990). Ex Corde Ecclesiae. Constitución apostólica sobre las universidades católicas. Disponible en http:// w2.vatican.va/content/john-paul-ii/es/ apost_constitutions/documents/hf_jpii_apc_15081990_ex-corde-ecclesiae. html

Lowney, C. (2005). El liderazgo al estilo de los jesuitas. Barcelona: Granica.

Nicolás, A. (2010). Profundidad, universalidad y ministerio intelectual. Retos para la educación superior jesuita hoy. Disponible en http://www.sjweb.info/documents/ansj/100423_Mexico_ESP.pdf

Pablo VI (1974). Discorso del Santo Padre Paolo VI in occasione della XXXII Congregaziones Generale della Compagnia di Gesù. Disponible en http:// www.vatican.va/holy_father/paul_vi/ speeches/1974/documents/hf_p-vi_ spe_19741203_esortazione-compagnia-gesu_it.html

Ruiz Jurado, M. (2014). Obras de San Ignacio de Loyola. Madrid: BAC.

Vivanco, B. (2013). La educación superior de la Compañía de Jesús y la promoción de la justicia. Formulación de propuestas, selección de buenas prácticas y análisis de la actitud del personal adscrito a las universidades jesuitas de España [Tesis doctoral inédita]. Universidad de Deusto: Bilbao.

\section{Otras fuentes}

Compañía de Jesús (1966). Congregación General XXXI. Documentos. Zaragoza: Hechos y Dichos.

Compañía de Jesús. Congregación Genera XXXII de la Compañía de Jesús. Madrid: Razón y Fe, 1975. Disponible en http:// www.sjweb.info/sjs/documents/CG32_ D2_esp.pdf

Compañía de Jesús. Congregación General 34 de la Compañía de Jesús. Bilbao: Mensajero, 1995. Disponible en http:// www.sjweb.info/documents/education/CG34_D17_SPA.pdf

Compañía de Jesús. Congregación General 35 de la Compañía de Jesús. Bilbao: Mensajero, 2008. Disponible en http:// www.sjweb.info/35/documents/Decretos.pdf

Compañía de Jesús. Congregación General 36 de la Compañía de Jesús. Roma: edición privada de la Compañía de Jesús, 2016. Disponible en http://www.gc36.org/

Liderazgo ignaciano. Bilbao: edición privada de la Provincia de Loyola, 2012.

Nicolás, A. Las instituciones apostólicas al servicio de la misión. Carta a todos los superiores mayores (Roma, 2 de febrero de 2014).

Nicolás, A. Sobre los jesuitas destinados al apostolado intelectual. Carta a toda la Compañía (Roma, 24 de mayo de 2014). 